\title{
REGIÃO, DIVERSIDADE TERRITORIAL E GLOBALIZAÇÃO
}

\author{
ROGÉRIO HAESBAERT \\ Universidade Federal Fluminense
}

Não pensamos que a região haja desaparecido. O que esmaeceu foi a nossa capacidade de reinterpretar e de reconhecer o espaço em suas divisões e recortes atuais, desafiando-nos a exercer plenamente aquela tarefa permanente dos intelectuais, isto é, a atualização dos conceitos.

(SANTOS, 1994:102)

A região continua a existir, mas com um nível de complexidade jamais visto pelo homem. Agora, nenhum subespaço do planeta pode escapar ao processo conjunto de globalização e fragmentação, isto é, de invidualização e regionalização.

(SANTOS, 1999:16)

Este artigo, que se pretende o embrião de um trabalho de maior fôlego sobre a questão regional, busca realizar uma avaliação preliminar da chamada Geografia Regional num contexto mundial de globalização. Discutiremos assim a relevância das questões regionais na atualidade, alguns dos fundamentos pelos quais se produz a diversidade territorial, base para qualquer proposta de regionalização, e as principais polêmicas em torno de uma redefinição do conceito de região.

\section{A pertinência da questão regional}

A questão regional retoma hoje sua força, não apenas nas ciências sociais, em função de vários debates acadêmicos, como também pela proliferação de regionalismos, identidades regionais e de novas-velhas desigualdades tanto a nível global como intranacional. Apesar da propalada globalização homogeneizadora o que 
vemos, concomitantemente, é uma permanente reconstrução da heterogeneidade e da fragmentação via novas desigualdades e recriação da diferença em todos os cantos do planeta. Um certo retorno às singularidades e ao específico ficam evidentes em correntes como o pós-modernismo e o pós-estruturalismo, denominações que evocam a crise social e de paradigmas em que estamos mergulhados, o que exige um constante questionamento de nossas proposições conceituais. Deste modo, pretendemos problematizar a questão regional a partir dos chamados processos de globalização que são, na verdade, sempre, processos concomitantes de globalização e fragmentação (HAESBAERT, 1998). Nesta problematização consideraremos as novas formas de manifestação da diversidade territorial à qual está ligada a regionalização, assim como as novas escalas em que se dá a manifestação dessa diversidade.

A relevância da questão regional não está ligada apenas à realidade concreta que mostra uma nova força das singularidades, um revigorar dos localismos/regionalismos e das desigualdades espaciais. A mídia também alimenta uma revalorização do "regional", ainda que ele seja entendido de maneiras as mais diversas. Para alguns, uma nova valorização do regional aparece no próprio bojo da globalização dos mercados e das comunicações ${ }^{1}$, o regional aí sendo interpretado como uma revalorização do singular, da diferença; para outros, a nova "regionalização" seria um contraponto à globalização, via criação de grandes uniões comerciais - como se os mercados comuns não estivessem inseridos numa articulação crescente aos circuitos globais da economia capitalista.

A nível teórico podemos reconhecer, nas últimas décadas, a amplitude da questão: regionalismos, identidades regionais e/ou regiões são ou foram abordados tanto pela Ciência Política (desde o legado de Gramsci e a questão meridional italiana como questão regional), pela Economia regional (como nos trabalhos de Perroux, Boudeville, Richardson e Isnard), pela Sociologia (vide trabalhos de Bourdieu e Giddens), pela Antropologia e pela História regional. Isto sem falar em áreas ligadas às ciências naturais, onde começam a surgir conceitos como o de "bio-região", numa correspondência entre "identidade biofísica e cultural" (McGINNIS et al., 1999).

Na Geografia em língua estrangeira temos um revigorar da Geografia Regional principalmente entre geógrafos de língua inglesa, como Gilbert (1988), Thrift (1990, 1991, 1993, 1996), Entrikin (1990, 1994), Hauer (1990) e Storper (1997). Na França, cabe lembrar a reedição de "A região, espaço vivido", de Frémont (1999) e o compêndio de "Iniciação à Geografia Regional”, de Claval (1993). No

\footnotetext{
1. Segundo o colunista social Wesley Sathler, da TV Vitória (ES), "a televisão caminha em direção à regionalização, como nos Estados Unidos. 'Você não pode ter preconceito com o regional. (...) Se você tem a opção de mudar de canal e deparar com um programa que mostra a sua comunidade ali lugares por onde você passa, pessoas que você conhece, empresas com as quais você trabalha - isso sempre vai ser mais interessante"”. (Jornal do Brasil, 8 ago. 99)
} 
caso da Geografia brasileira devemos destacar trabalhos das últimas duas décadas como os nossos próprios (Haesbaert, 1988, 1997), Corrêa (1986), Gomes (1988, 1995), Castro (1992), Heidrich (1999) e Albuquerque (1998).

Gilbert (1988) afirma enfaticamente:

(...) os geógrafos estão redescobrindo o estudo do específico. (...) a geografia está começando a ver aqueles sistemas e estruturas [aos quais estava inteiramente dedicada] como localizações e a reexaminar a especificidade dos lugares. (...) Esse interesse renovado pelo específico faz ressurgir alguns dos conceitos dos estudos regionais e pode assim ser interpretado como um retorno à corologia. Entretanto, devemos considerar (...) que a geografia regional praticada desde a metade da década de 1970 é uma nova geografia regional. (p. 208)

Ao lado dessa "nova geografia regional" no âmbito acadêmico devemos lembrar também a proliferação do que podemos denominar "geografias regionais populares", num interesse revigorado pelas singularidades que marcam o espaço geográfico, como bem o demonstra a crescente difusão de revistas e vídeos como os da National Geographic, que acaba de lançar sua revista em língua francesa. Mas sem dúvida uma das áreas que mais tem estimulado a diversidade territorial, através da valorização e/ou da re-criação da diferença (quando não do exótico) é o turismo, um dos setores mais dinâmicos da economia contemporânea.

De saída, é importante explicitarmos alguns dos pressupostos a partir dos quais propomos trilhar estas reflexões. Em primeiro lugar, admitimos que regionalização é um processo amplo, instrumento de análise para o geógrafo em sua busca dos recortes mais coerentes que dêem conta das diferenciações no espaço. Por outro lado, região, como conceito, envolve um rigor teórico que restringe seu significado mas aprofunda seu poder explicativo; para defini-la devemos considerar problemáticas como a das escalas e fenômenos sociais mais específicos (como os regionalismos políticos e as identidades regionais) entre aqueles que produzem a diversidade geográfica do mundo.

\section{Região: entre o velho e o novo}

Antes de abordarmos as bases que envolvem a diversificação do espaço geográfico contemporâneo, é importante, ainda que de forma bastante sucinta, retomar as raízes da análise regional e do conceito de região, de acordo com algumas das linhas teóricas até aqui focalizadas pela Geografia.

Devemos relembrar sobretudo nossos clássicos, responsáveis por uma "paternidade" da região em Geografia, especialmente Vidal de La Blache, Carl Sauer e Richard Hartshorne. Estes autores, em distintas perspectivas, enfatizaram a "diferenciação de áreas" como questão fundamental para o trabalho do geógrafo. Mas 
enquanto La Blache via a região como "algo vivo", uma "individualidade" ou mesmo uma "personalidade geográfica", Hartshorne a encarava como um constructo intelectual e que, como tal, poderia variar em sua delimitação de acordo com os objetivos do pesquisador. Já Sauer, com um grau de racionalismo que parece ficar a meio caminho entre La Blache e Hartshorne, buscava na Geografia regional uma "morfologia da paisagem" que não se preocupava apenas com o único, o singular, mas também com a comparação dessas "paisagens individuais", num "sentido corológico pleno, isto é, a ordenação de paisagens culturais"2.

Apesar de suas divergências em relação ao enfoque regional, podemos afirmar que são pontos comuns entre os três autores:

- a importância dada ao específico, ao singular - aquilo que La Blache vai denominar de "personalidade geográfica" e Hartshorne de "diferenciação de áreas"; apesar de não serem partidários de um empirismo baseado na descrição simplista de características únicas, como muitos alegam, os três autores muito menos são defensores irrestritos de um racionalismo lógico-analítico ${ }^{3}$;

- o estudo integrador ou de "síntese" que permite perceber uma coesão/coerência interna à região, envolvendo as múltiplas dimensões do espaço geográfico, a começar pelas "humanas" e "naturais". 4

2 "A geografia regional é morfologia comparada, o processo de comparar paisagens individuais em relação com outras paisagens". (SAUER, 1998 [1927]: 60)

3 . É curioso observar como os três autores propuseram métodos próprios, às vezes um tanto ecléticos, de análise regional, sem nunca, entretanto, cair no simplismo de um método exclusivamente empirista (embora num sentido geral este seja predominante) ou objetivo-racionalista. Sauer, por exemplo, ao mesmo tempo que defende um "método morfológico", "empírico" (1998:30-31) de estudo da paisagem, afirma também que a paisagem geográfica "não é simplesmente uma cena real vista por um observador. A paisagem geográfica é uma generalização derivada da observação de cenas individuais", um "tipo", pois o geógrafo "tem sempre em mente o genérico e procede por comparação" (1998:24). Mesmo La Blache (1994 [1903]), sempre lembrado pelas suas proposições empiristas, deixa clara sua preocupação com relações mais gerais em expressões como "os efeitos incoerentes de circunstâncias locais, [o homem] substitui por um concurso sistemático de forças" e a "personalidade" geográfica "corresponde a um grau de desenvolvimento já avançado de relações gerais" (p. 20). Gomes (1996) enfatiza esta interpretação mais complexa do pensamento lablacheano, "cruzamento de influências", e mostra também as ambigüidades do pensamento de Hartshorne, o mais racionalista dos três.

4. Nas palavras de Sauer, "ao se dar preferência ao conhecimento sintético de áreas para a ciência geral da terra, estaremos de acordo com toda a tradição da geografia" (1998:17). Para ele, vários geógrafos, incluindo La Blache, teriam reafirmado a "tradição clássica da geografia como relação corológica" (p. 21), por ele também partilhada, como fica evidente em sua concepção de paisagem: "uma área composta por uma associação distinta de formas, ao mesmo tempo físicas e culturais" (p. 23, grifo nosso). Sobre esta "síntese" humano-natural, La Blache afirma que "uma individualidade geográfica (...) não é uma coisa dada de antemão pela natureza. (...) É o homem que, ao submetê-la ao seu uso, ilumina sua individualidade" (VIDAL DE LA BLACHE, 1994:20). 
- a continuidade espacial - nenhum deles trabalha com regiões fragmentadas ou descontínuas, embora Hartshorne admita (criticamente) esta proposição.

- a estabilidade regional - embora mais visível na obra de La Blache ${ }^{5}$, esta estabilidade - sempre relativa - fica implícita nas propostas de Sauer e Hartshorne (que na revisão de seu The Nature of Geography discute de modo mais incisivo os fluxos e as regiões funcionais).

- a relação entre região e uma "meso-escala" de análise, aspecto este não exatamente proveniente da abordagem desses três autores, mas de uma tradição mais ampla em Geografia Regional; esta meso-escala estaria geralmente situada num nível sub ou infra-nacional, imediatamente referida ao Estado-nação.

É importante destacar o grau de abrangência do conceito, que se tornou com certeza o mais pretensioso dentro da Geografia e, talvez por isto mesmo, também aquele que é mais nitidamente reconhecido como um conceito geográfico por outros cientistas sociais. Mesmo uma concepção mais ampla como a de território acaba, a priori, privilegiando uma dimensão social, geralmente a dimensão política (v. por exemplo as propostas de Raffestin, 1980, e Sack, 1986), enquanto paisagem, por sua vez, aparece com muita freqüência vinculada à dimensão simbólicocultural. Mas, mesmo perdendo terreno para concepções como as de território, rede e paisagem, a região nunca deixou de ser um instrumento de trabalho para o geógrafo, isto sem falar nos planejadores, nos políticos e nos militares. ${ }^{6}$

Um dos problemas centrais levantados pela questão regional no âmbito acadêmico refere-se à busca da síntese entre múltiplas dimensões do espaço geográfico, síntese esta que, sem ser exaustiva, está vinculada à produção de uma singularidade coerente capaz de delimitar uma porção contínua e relativamente estável do espaço. Na prática, se La Blache foi quem teve mais sucesso nesta empreitada, a maioria dos geógrafos acabou priorizando uma dimensão do espaço: seja a dimensão natural, nas regionalizações do século XIX, a dimensão urbano-econômica, nas regiões funcionais, ou a dimensão política, mais recentemente enfatizada no vínculo região-regionalismo. Na busca do(s) elemento(s) integrador(es) o geógrafo muitas vezes caiu na simplificação generalista de um método pretensamente "comple-

\footnotetext{
${ }^{5}$ Mesmo reconhecendo que "revoluções econômicas como aquelas que se desdobram nos nossos dias imprimem uma agitação extraordinária à alma humana", La Blache considera que "este distúrbio não deve nos subtrair o fundo das coisas. (...) $\mathrm{O}$ estudo atento daquilo que é fixo e permanente nas condições geográficas da França deve ser ou deve tornar-se mais do que nunca o nosso guia". (VIDAL DE LA BLACHE, 1994[1903]:547, grifo nosso) Não se pode ignorar, entretanto, a distinção entre o La Blache do "Tableau" de 1903 e o de "Princípios de Geografia Humana", editado em 1921, com uma de suas três partes dedicada à circulação.

6. Yves Lacoste (1976) ressalta o papel fundamentalmente político da região, etimologicamente ligada ao caráter militar, pois vem do latim "regere", que significa "dominar, reger".
} 
xo", que tornou a análise (não atingindo a "síntese") regional um mero acúmulo de "gavetas", onde se sucediam relevo, clima, população, economia, etc.

Gilbert (1988) fala de uma "renovação da síntese regional" sob um não muito claro "modo pós-positivista de explicação do específico" (que hoje vai desde o marxismo e a teoria da estruturação de Giddens até o pós-estruturalismo). "Análise e síntese", diz ela, são "usados como complementares para entender a região" e seu caráter singular. A síntese seria antecedida de uma base teórica que passa a considerar a especificidade regional como resultado "da interconexão de processos em diferentes escalas, processos não necessariamente complementares, sem dúvida freqüentemente antagônicos". (1988:220)

Fica evidente que, num mundo dito em processo de globalização, falar em estabilidade e continuidade (física) dos fenômenos no espaço é muito problemático. Ainda no início do século La Blache já demonstrava (apesar do que afirmam muitos dos seus críticos) que analisar uma região da França ou a França no seu conjunto demandava também analisar contextos mais amplos, na escala da Europa, por exemplo. Esta sobreposição das escalas de ocorrência dos fenômenos sociais, muito mais intrincada no mundo contemporâneo, dificulta a análise regional na medida em que é muito raro encontrar espaços "coerentes" e cuja especificidade possa ser analisada independente de sua inserção em processos visíveis em outros níveis escalares. Regionalizar num mundo em globalização é uma tarefa duplamente difícil: como se pode dividir o que em tese está em crescente processo de integração? Como se pode distinguir espaços num mundo que se diz em processo de homogeneização?

Retomando as características apontadas acima para os estudos regionais clássicos, podemos dizer que permanecem como duas questões centrais, articulando a Geografia Regional ao longo de todo o seu percurso:

- o estudo integrador ou "de síntese", seja ele mais seletivo (quando seleciona um fato ou dimensão do espaço geográfico mais significativo para a definição desta integração regional), ou mais amplo. É verdade que todas as áreas/disciplinas realizam sínteses, mas ao geógrafo cabe uma síntese muito complexa e particular, por se concentrar no espaço enquanto condensação de múltiplas manifestações sociais.

- o estudo das especificidades, da "diferenciação de áreas" ou ainda, para utilizar um termo menos carregado de um legado empirista, da diversidade territorial; apesar de toda a uniformização promovida através da globalização capitalista, torna-se imprescindível discutir e encontrar formas de distinguir espaços/regiões, pois no nosso entendimento a diversidade territorial continua sendo um leitmotiv fundamental na construção da Geografia.

Talvez pudéssemos mesmo afirmar que uma das explicações para a timidez do geógrafo em se afirmar frente a outras áreas nas ciências sociais esteja no fato de 
ele não assumir que a "natureza da Geografia" depende em grande parte de uma visão do espaço como um conjunto integrado, uma "condensação" ou "síntese" (com toda a ambigüidade que este termo implica) de múltiplas dimensões que as análises regionais, bem ou mal, sempre procuraram alcançar. Mas, se num mundo em processo de globalização/des-territorialização temos mais dificuldade em encontrar áreas coesas (ou "integradas") e coerentes, cabe verificar qual a nova lógica da regionalização a partir dessa recriação da diversidade territorial. É o que procuraremos discutir a seguir.

\section{Diversidade territorial e regionalização}

Em meio às mutações de acordo com a abordagem teórico-filosófica, a Geografia Regional acabou sempre respondendo, em primeiro lugar, à questão: qual é o principal agente responsável pela produção da diversidade geográfica? No final do século XIX ainda eram fortes as correntes deterministas/ambientalistas que entendiam que o espaço deveria ser interpretado antes de mais nada pela diferenciação "natural" da superfície terrestre. Herbertson (1905), por exemplo, realizou uma grande regionalização do mundo em regiões naturais. Aos poucos os homens, os grupos sociais, foram predominando na interpretação dos geógrafos e com eles vieram o espaço agrário, as cidades (logo transformadas em nós ou pólos articuladores das regiões, que La Blache já denominava de "regiões nodais"), os eixos de transporte etc. Da diferenciação baseada no uso agrícola do solo passouse logo à industrialização, ao comércio e aos serviços.

Numa ótica ainda carregada de positivismo/funcionalismo, introduziram-se noções de região menos estáticas como a de centro-periferia, também reinterpretada numa visão crítica pelo marxismo. Embora tenha inicialmente rechaçado o conceito de região (LACOSTE, 1976), a vertente do materialismo histórico recuperou a análise regional a partir, primeiro, da noção de divisão territorial (ou espacial, na leitura de Massey, 1984) do trabalho e, depois, a partir do regionalismo político (MARKUSEN, 1981). Hoje encontramos uma multiplicidade de interpretações sobre região e regionalização. Como alguns não admitem uma leitura geral do espaço sob um mesmo critério integrador/ diferenciador, a diversidade territorial nem sempre se torna sinônimo de diversidade regional, pois, para muitos geógrafos, nem todo recorte coerente do espaço geográfico é uma região - apenas aqueles que se referem a processos específicos como os movimentos regionalistas e as identidades regionais. Aqui, portanto, os processos responsáveis pela formação de regiões acabam interligando o político, o econômico e o cultural.

Num sentido mais amplo, qualquer iniciativa no sentido de analisar a diversidade territorial implica em reconhecer a relação particular-geral e singular-universal, de modo a não cair nem em estudos de caso que sirvam simplesmente para corroborar uma visão geral, como muitas vezes ocorre na concepção de região como 
produto da divisão territorial do trabalho, nem em estudos específicos que nada dizem sobre relações sociais mais amplas, como ocorria em algumas leituras empiristas da geografia clássica.

Cabe a uma Geografia Regional renovada recuperar o sentido dos recortes espaciais tanto a partir de sua inserção desigual em movimentos mais globalizados quanto a partir da re-criação de singularidades que lhes dão um carater próprio. Revalorizar o singular não significa cair outra vez numa "fenomenologia pura", que vê somente o "acontecimento", ou num empirismo bruto, baseado no binômio observação-descrição; significa, isto sim, evidenciar a capacidade dos grupos humanos de recriar espaços múltiplos de sociabilidade.

Sintetizando, são questões fundamentais:

- para entender a diversidade territorial devemos priorizar a diferença em sentido estrito ou a desigualdade, o par singular / universal ou particular / geral?

- a regionalização seria aplicável apenas a alguns espaços, ligada a fenômenos sociais específicos, ou seria referida ao espaço geográfico no seu conjunto?

Smith (1988) afirma que se pode ver a "formulação regional" como um "compromisso geográfico" entre equalização e diferença e entre fixidez e fluidez no espaço (p. 150). Pretendemos focalizar aqui o "compromisso", não exatamente entre equalizaçao e diferença, mas entre des-equalização (ou desigualdade) e diferença.

Ao observarmos as correntes geográficas que enfocaram a regionalização, percebemos que algumas entendiam a diversidade territorial mais pelo viés da diferença, em sentido estrito, ou seja, da singularidade, como é o caso da geografia regional lablacheana, e outras mais pela perspectiva da desigualdade, tomando um padrão de medida como referência para, em função dele, situar cada região. Nesta segunda perspectiva encontra-se a região como produto da divisão territorial do trabalho ou as regiões funcionais, hierarquizadas de acordo com a área de influência das cidades.

As abordagens funcionalistas sobre a região negligenciam a dimensão específica do vivido. Como afirma Entrikin (1991), "caracterizar lugares como todos funcionais ou como sistemas regionais tem uma utilidade clara no planejamento de atividades ou na vida cotidiana, quando vemos o lugar como algo que nos é exterior e como algo a ser manipulado para fins particulares." Esta concepção funcional de lugar e região "é, contudo, um constructo intelectual que abstrai as qualidades contextuais específicas que proporcionam a sua significância existencial" (p. 131). Deste modo, autores contemporâneos dão ênfase também ao espaço vivido (FRÉMONT, 1976) e às identidades territoriais na produção da diversidade geográfica.

Aliar a construção "sistêmica" das desigualdades, principalmente aquela promovida pela (des)ordem econômica, com a produção diferenciadora das singularida- 
des, da vivência do espaço e da nossa identificação com ele, torna-se ao mesmo tempo um desafio e uma necessidade. A Geografia Regional, que nasce de uma outra dicotomia geográfica, aquela entre Geografia Regional e Geografia Geral ou Sistemática, tem a obrigação de não alimentar novos dualismos e, sempre que possível, afirmar sua pretensão integradora. Como observou Hartshorne (1978), a Geografia não pode ser considerada dividida entre análises tópicas, sistemáticas (a análise de "elementos individuais através do mundo"), e análises integrativas, "regionais" (a "análise de áreas" ou de "conexões de fenômenos em integração").

Temos a partir daí duas conotações do regional: análise de elementos individuais, específicos, "regionalmente" localizados, e análise integradora, mais "totalizante", observando a integração de múltiplos fenômenos numa área (integração esta que depende, como já ressaltamos, de uma escolha teórica desses elementos integradores). Com certeza uma visão integrada do espaço geográfico irá revelar sua combinação específica, não reprodutível da mesma forma em outra área. Mas ao mesmo tempo ela reúne elementos presentes, sob outras formas de articulação, em outros espaços. Daí a possibilidade - e necessidade - de se trabalhar sempre, em qualquer análise geográfica, tanto com elementos singulares/especifícos, e universais, quanto com elementos particulares (parte de um todo) e gerais. Isto sem dicotomizá-los, já que não há nenhum limite claro entre eles - muitos fenômenos são produzidos concomitantemente como singulares/universais e como particulares/gerais. Diretamente envolvida nesta problemática encontramos a questão das relações global-local, que será abordada mais adiante.

Num sentido mais amplo, devemos nos indagar agora sobre as razões que justificam, hoje, em plena dinâmica globalizadora, a produção da diferença/diversidade em sua manifestação territorial. Para entendermos a produção da diversidade territorial no mundo contemporâneo é necessário pensar, antes de mais nada, nos binômios (mas não num raciocínio binário) desigualdade-diferença e globalizaçãofragmentação através das relações global-local.

\section{0 des-igual e o diferente}

A diversidade territorial do mundo contemporâneo é resultado da imbricação entre duas grandes tendências ou lógicas sócio-espaciais, uma decorrente mais dos processos de diferenciação/singularização, outra dos processos de des-igualização, padronizadores (mas nem por isso homogeneizantes). Podemos mesmo associar esta questão com aquilo que Gibson (1998) denomina os dois discursos distintos que marcam a interpretação da vida social nos anos 80 e 90: os debates em torno da "polarização social", que priorizam a desigualdade econômica e a estratificação em classes sociais, e as teorias ou "representações da diferença", que valorizam a construção social do gênero, etnia, sexualidade etc. 
O par desigual-diferente corresponde aproximadamente à distinção feita pelo filósofo Bergson (1989 [1934]) entre "diferenças de natureza", qualitativas, e "diferenças de grau ou de intensidade", mais quantitativas. O desigual ou, em outras palavras, a diferença de grau, exige sempre a referência a uma escala de valores-padrão frente à qual os processos são comparados, medidos ou mesmo hierarquizados, pois em toda medida entra um elemento de convenção. Mesmo sem entrar aqui nas bases complexas da filosofia bergsoniana, que se volta para a apreensão do movimento e não da imobilidade, da intuição e não da análise, ressaltaríamos a relevância que adquire, para o autor, a busca das "diferenciações e das integrações qualitativas", em contraponto à análise quantitativa, este "retrato imóvel" que nossos esquemas conceituais mais comumente implicam.

Regionalizar não é simplesmente recortar o espaço a partir de parâmetros genéricos, quantitativos, diferenças de grau como faixas de renda, produto interno bruto, fluxos comerciais etc. Deve envolver, igualmente, as diferenças de natureza como aquelas de ordem mais estritamente cultural. Partiremos então do pressuposto de que a diversidade territorial, enquanto fundamento para a regionalização em seu sentido mais geral, se manifesta sob duas grandes formas:

- a produção de particularidades, do desigual (diferenças de grau), que vincula os espaços em distintas escalas;

- a produção de singularidades, do específico (diferenças de natureza), em geral mas não exclusivamente de base local e sem correlação obrigatória com realidades geográficas em outras escalas.

Estas duas manifestações, embora participando de um jogo complexo de articulações mútuas na permanente transformação dialética da quantidade em qualidade, estão vinculadas a dois processos no bojo da des-ordem sócio-espacial contemporânea:

- o aviltamento das desigualdades pelo capitalismo global altamente seletivo e, portanto, excludente;

- o reafirmar das diferenças por movimentos sociais baseados no resgate ou reconstrução de identidades (religiosas, étnicas, nacionais etc.).

Evidenciando a dialética de inclusão-exclusão entre estes dois movimentos podemos também afirmar que, no que diz respeito a esta re-afirmação das diferenças, ela tem duas faces, uma que é mais um produto da própria globalização dominante, outra que é mais uma resistência a este movimento globalizador/ des-igualizante.

As diferenciações espaciais são fruto da globalização na medida em que o reforço da economia de mercado se dá via "diversificação" do consumo, pois "diversidade vende" (HERBERTSON, 1995). Assim, por exemplo, novos nichos de mercado são criados em função da valorização de hábitos locais/regionais. 
Por outro lado, a reativação de identidades culturais que a globalização tenderia a debilitar pode também manifestar sua outra face: a da resistência a estes processos globais. Assim, manifestar diferenças "incomparáveis" ligadas à religião, à etnia ou à língua pode ser uma forma de ir contra a dinâmica globalizadora, como no caso de alguns movimentos radicais muçulmanos.

Por fim, essa re-afirmação da diferença, principalmente aquela que se dá pela maior mobilidade das pessoas (seja como turistas, como migrantes ou como refugiados), pode instaurar não apenas a resistência via formação de guetos, por exemplo, mas também os hibridismos culturais (HALL, 1997 [1992]; CANCLINI, 1997 [1992]) voltados para contatos e interações culturais muito mais intensas. Isto manifesta uma nova lógica das relações global-local, perspectiva mais geográfica dos processos de diferenciação e igualização (ou de heterogeneização e homogeneização), que será discutida a seguir.

\section{A dinâmica global-local}

Ao lado do par globalização-fragmentação, tão difundido hoje, encontramos um outro binômio, mais explicitamente espacial, pois envolve duas escalas geográficas: o global-local. As relações globais-locais (e vice-versa) são consideradas hoje uma das formas mais contundentes em que se pode perceber a dinâmica da des-equalizaçãodiferenciação. Muitos autores vêem, de forma simplista, o global associado com processos de totalização, de generalização/universalização, e o local com processos de fragmentação, de particularização/singularização, como se o global fosse o locus da homogeneização e o local o da heterogeneização. Vários outros estudiosos mostraram que a questão é muito mais complexa. Robertson (1995) chegou mesmo a propor o termo "glocalização", considerado mais coerente para dar conta dessa relação.

A luta entre uma face homogeneizadora e uma face heterogeneizadora demonstra que processos globais "implantam-se" no local, adaptando-se a ele, ao mesmo tempo em que o local pode globalizar-se na medida em que expande pelo mundo determinadas características locais. No primeiro caso ocorre uma dinâmica no sentido global-local, mas sem que o local seja um simples reflexo do global, pois ele impõe condições para a realização da globalização. No segundo caso, o local produz a diversidade no âmbito global, complexificando as características que marcam a globalização. Esta dinâmica local-global pode envolver desde circuitos globais "paralelos" ou não-integradores (para quem está fora dos seus circuitos), como o das grandes diásporas imigrantes, até circuitos globais integradores, como o de um valor ou hábito local que se projeta para vários outros grupos ao redor do mundo (o que aconteceu com a culinária chinesa e japonesa, por exemplo).

É importante destacar que os circuitos globais podem ter tanto um caráter geral, mais disseminado, como é o caso das redes informacional e financeira, quanto um caráter segmentado, envolvendo grupos e culturas específicos, como ocorre nas 
diásporas mundiais (chinesa, indiana, japonesa) e nas redes ilegais do contrabando e do narcotráfico. A escala cartográfica de atuação, em ambos os casos, é a mesma - o globo, mas o "recorte" aí privilegiado é distinto. Enquanto as redes informacional e financeira envolvem agentes com uma intenção clara de expandir ao máximo sua atuação (embora na prática continuem sempre seletivos), as diásporas mantêm laços atrelados à sua etnia ou grupo nacional, e o caráter "ilegal" dos circuitos do narcotráfico sugere sempre uma clandestinidade que se vê retratada na dimensão espacialmente mais restrita que eles ocupam na sociedade.

Mais do que a distinção entre estes circuitos, devemos observar a vinculação entre eles, na medida em que os circuitos globais transformam e são transformados por fenômenos de nível dominantemente local. O que, entretanto, estamos denominando de local? Devemos reconhecer a existência de pelo menos três abordagens:

- o local vinculado aos processos gerais de heterogeneização/diferenciação (frente a um "global" de tendências homogeneizadoras e universalizantes);

- o local como instrumento de análise, escala geográfica de abordagem (envolvendo as relações sociais ligadas ao cotidiano e aos contatos face-a-face);

- o local como lugar (este geralmente entendido como um espaço culturalmente signicativo, dotado de valor subjetivo).

Tomando esta última abordagem, muito rica em seu conteúdo geográfico, percebemos também enfoques distintos. Na verdade os termos local e lugar são muito ambíguos. Para Giddens (1991), por exemplo, muitas vezes o lugar adquire o mesmo significado de local, na medida em que "lugar" seria "melhor conceitualizado por meio da idéia de localidade, que se refere ao cenário físico da atividade social como situado geograficamente" (p. 26-27). Ele admite, porém, que, sob condições de modernidade, promovendo "relações entre ausentes" e "desencaixando" assim o tempo do espaço, o lugar pode incluir o global, na medida em que "o lugar se torna cada vez mais fantasmagórico; isto é, os locais são completamente penetrados e moldados em termos de influências sociais bem distantes deles” (p. 27). ${ }^{7}$

\footnotetext{
${ }^{7}$ Mais adiante ele deixa ainda mais nítida esta correspondência entre lugar e local ao afirmar que "a modernidade 'des-loca' no sentido anteriormente analisado - o local [antes era o lugar] se torna fantasmagórico" (Giddens, 1991:141). A posição de Castells (1999) parece mais restrita que a de Giddens, ao pensar o lugar como "um local cuja forma, função e significado são independentes dentro das fronteiras da contigüidade" (p. 447), "um espaço interativo significativo, com uma diversidade de usos e ampla gama de funções e expressões" (p. 448-449).

8 A "re-criação da localidade" envolve a "re-criação de lugares de relativa pequenez e informalidade" (GIDDENS, 1991:142), pois o "reencaixe" espaço-tempo corresponderia à "reapropriação ou remodelação de relações sociais desencaixadas de forma a comprometê-las (embora parcial ou transitoriamente) a condições locais de tempo e lugar" (p. 83). Lembre-se que por "desencaixe [dos sistemas sociais]" Giddens se refere "ao 'deslocamento' das relações sociais de contextos locais de interação e sua reestruturação através de extensões indefinidas de tempo-espaço” (p. 29).
} 
Enquanto Giddens, confundindo muitas vezes escala local e lugar, em geral os associa com "espaços de co-presença" ou de "compromissos com rosto", de contatos face-a-face ${ }^{8}$, Lévy (1999) deixa implícita uma distinção entre local, enquanto escala cartográfico-matemática, instrumento de análise, poderíamos dizer, e lugar, enquanto concepção geográfica, no sentido de incorporar um conteúdo sócio-espacial específico. Ele propõe assim uma definição de lugar como "espaço em que se considera, por hipótese, que as distâncias separando os diferentes fenômenos que o compõem são nulas" (p. 316). O lugar pode então ser pequeno ou grande em termos físico-cartográficos. ${ }^{9}$ A anulação das distâncias promovida pelo "lugar", neste caso (via redes informacionais, por exemplo), não leva obrigatoriamente ao contato face-a-face, como indica Giddens - assim como poderíamos fazer a afirmação inversa, de que a anulação das distâncias no contato face-a-face não leva obrigatoriamente à anulação de outra e mais substantiva distância, aquela entre as pessoas.

A produção da diversidade territorial resulta, deste modo, de uma imbricação ou hibridização complexa entre as dimensões global e local, ou, em termos mais abstratos, universal e particular. Daí a pertinência do termo "glocal" tal como elaborado por Robertson (1995). Na verdade o que temos é um continuum de diferentes níveis de hibridização entre condições locais, diferenciadas/diferenciadoras, e condições globais, mais universalizantes, desde os "lugares-mundo", altamente conectados pelos fluxos globais, até os "lugares-tribo", em tentativas de fechamento em torno de valores exclusivistas, espacialmente segregados.

Numa perspectiva das relações global-local, o local pode ser atravessado pelos processos globais e, mesmo "fantasmagórico", continua sendo visto como o locus privilegiado dos contatos interpessoais. Numa outra perspectiva, os fenômenos de nível local podem "expandir-se" para o mundo, na medida em que a anulação das distâncias físicas pode se projetar, via meio técnico-científico informacional (SANTOS, 1994), para relações efetivamente globais. Não podemos esquecer que até mesmo relações pessoais mais íntimas também são construídas via circuitos "impessoais" como a Internet.

Neste jogo entre o local e o global não se trata apenas de uma globalização homogeneizadora, que padroniza as desigualdades, e de localismos diferenciadores que resistem, promovendo a heterogeneização. Assim como a globalização se condensa no nível local, um pouco no sentido da "compressão espaço-temporal" de Harvey (1989), e o local pode se projetar para o global numa espécie de "alongamento" ou "distanciamento tempo-espaço" (tomando por empréstimo o polêmico termo de Giddens), também sabemos que condições originalmente locais

\footnotetext{
${ }^{9} \mathrm{O}$ próprio mundo hoje estaria em parte se transformando num lugar pela mundialização, especialmente no que se refere à circulação de capital e informação, que se tornam "insensíveis à distância ou, mais simplesmente, funcionam sem distância" (LÉVY, 1999:316). A mundialização seria então tanto destruidora quanto construtora de lugares. Lévy, entretanto, subvaloriza a dimensão mais subjetiva do lugar.
} 
podem se tornar globais e que a própria globalização pode re-criar ou reinventar o local.

Desta forma, obviamente, a globalização não serve apenas para globalizar. Como já enfatizamos, a diferença (cultural) pode ser estimulada pelos circuitos econômicos globais, a fim de produzir novos nichos de consumo. E a "ideologia do lar" que o desenraizamento globalizador produz não é apenas uma reação contra a globalização, mas seu produto indissociável, no bojo deste processo mais amplo, capaz inclusive de reinventar o sentido de "lar"10.

Por fim, no sentido de local enquanto escala física, de contatos a curta distância, não podemos esquecer que a produção da diversidade territorial, embora manifeste uma tendência a ocorrer cada vez mais nos circuitos que vinculam escala local e escala global, na verdade continua se dando em múltiplas escalas; por exemplo, a escala nacional e os movimentos nacionalistas, que em contextos como o do exbloco socialista se manifesta com grande intensidade. Além disso, é fundamental reconhecer sempre que, paralelamente aos circuitos que vinculam local e global num "sistema-mundo" (DOLLFUS,1993), há toda uma massa de excluídos (a qual denominamos "aglomerados humanos de exclusão" [HAESBAERT, 1995]) que acaba produzindo suas próprias "diferenciações", não obrigatoriamente conectada a um ordenamento sistêmico.

\section{Questões sobre região e regionalização}

Tendo abordado, de forma genérica, os principais processos responsáveis pela produção da diversidade territorial, focalizaremos agora algumas questões centrais que se colocam para a análise regional. Antes disto, devemos retomar a distinção proposta entre região, enquanto conceito, e regionalização, enquanto método ou instrumento de análise. Como já afirmamos, partimos do pressuposto de que região e regionalização são concepções que envolvem posições teóricas distintas. Enquanto a região adquire um caráter epistemológico mais rigoroso, com uma delimitação conceitual mais consistente, a regionalização pode ser vista como um instrumento geral de análise, um pressuposto metodológico para o geógrafo e, neste sentido, é a diversidade territorial como um todo que nos interessa, pois a princípio qualquer espaço pode ser objeto de regionalização, dependendo dos objetivos definidos pelo pesquisador ${ }^{11}$.

\footnotetext{
${ }^{10}$ Robertson (1995) se refere à "invenção do local”, no mesmo sentido em que Eric Hobsbawm fala na "invenção das tradições".

${ }^{11}$ Daí a infinidade de recortes espaciais possíveis de serem produzidos pelos diversos métodos de regionalização, e que variam conforme o aspecto enfatizado na construção da diversidade territorial, desde aspectos naturais como o clima ("regiões" climáticas) até aspectos culturais ("regiões" culturais) ou econômicos.
} 
Com relação à região enquanto conceito e não como simples parcela do espaço, como é concebida no senso comum, gostaríamos de lembrar uma proposta, fruto de nosso trabalho sobre o regionalismo e a identidade no espaço conhecido como Campanha Gaúcha, em que conceituamos região como "um espaço (não institucionalizado como Estado-nação) de identidade ideológico-cultural e representatividade política, articulado em função de interesses específicos, geralmente econômicos, por uma fração ou bloco 'regional' de classe que nele reconhece sua base territorial de reprodução" (HAESBAERT, 1988:25). Tentamos integrar aqui as dimensões econômica, política e cultural, numa dialética em que o espaço regional é ao mesmo tempo um espaço de reprodução econômica, locus de representação política (efetiva ou almejada) e um espaço de identidade cultural. É claro que esta "diversidade territorial" não cobre todos os espaços.

Alguns autores, de forma mais ampla, mas sem perder de vista este caráter condensador de múltiplas dimensões, definem região tentando incluir até mesmo a dimensão natural, negligenciada em propostas como a nossa, acima apresentada. É interessante ressaltar que uma dessas conceituações, a de Markusen (1987), veio na seqüência de outra proposta da mesma autora (MARKUSEN, 1981) em que ela tentava negar a relevância do espaço, utilizando o termo "regionalismo" no lugar de "região" a fim de não "reificar" o espaço, "subordinando o espacial ao social".

Markusen (1987:16-17) definiu região como "uma sociedade territorial contígua, historicamente produzida, que possui um ambiente físico, um milieu [meio] sócio-econômico, político e cultural distinto de outras regiões e em relação a outras unidades territoriais básicas, a cidade e a nação". Permanecem na concepção da autora alguns princípios gerais que quase sempre marcaram o conceito de região, como contigüidade, caráter integrador entre múltiplas dimensões, diferenciação espacial ("milieu distinto") e escala subnacional.

Cabe então perguntarmo-nos quais destas características ainda são defensáveis diante dos processos sociais e da produção do espaço em um mundo dito globalizado. Retomemos e ampliemos aqui a discussão daquelas características enunciadas ao final da análise de nossos clássicos (La Blache, Sauer e Hartshorne):

- a singularidade ou "diferenciação espacial";

- a coesão e a integração entre múltiplas dimensões do espaço;

- a estabilidade e a continuidade/contigüidade regional;

- a escala ("meso-escala", escala subnacional e/ou local).

Se essas eram propriedades reconhecidas naquelas primeiras propostas de um discurso regional mais articulado, como elas podem ser vistas na atualidade? Embora seja muito difícil, pelas limitações deste artigo, aprofundar o debate sobre questões tão amplas e polêmicas, iremos pelo menos explicitar algumas idéias gerais preliminares. 
Primeiro, com relação à especificidade/singularidade regional: vimos que ainda ocorre uma "diferenciação de áreas" e que a diversidade territorial continua a se difundir, apesar da relativa homogeneização promovida pelos processos globalizadores, especialmente aqueles ligados aos circuitos econômicos do capitalismo globalizado. Esta diferenciação, porém, se dá sob novas bases, inclusive com a diversidade sendo produto da própria dinâmica globalizadora. Trata-se de um processo que sempre associa a diferença de grau e a diferença de natureza, nos termos de Bergson, sem entretanto confundi-las. Aqui, a região como produto genérico da diversidade territorial adquire sua conotação mais ampla. Defini-la apenas do ponto de vista da diferença stricto sensu (diferença de natureza) seria uma temeridade e, de certa forma, um retorno às visões empiristas que mais criticamos. Por outro lado, ver apenas a diversidade territorial/regional sendo produzida pela diferença de grau, como em muitas regionalizações ligadas à divisão territorial do trabalho ${ }^{12}$, também simplificaria a complexidade dos espaços, vendo-os apenas na sua dimensão econômico-funcional.

Em relação à coerência, integração ou coesão interna aos espaços regionais e sua continuidade espacial, ninguém deveria hoje utilizar o termo "região homogênea", por mais "coerente" e "contínua" que uma área pareça. A unidade geográfica, se é que ela ainda é defensável em termos de integração e continuidade espacial, tem uma coesão muito dinâmica. O que não podemos negar é a relevância e mesmo a necessidade, permanente, de identificar recortes espaciais, por mais mutáveis que eles sejam. Ainda que eles não sejam reconhecidos como regiões em sentido estrito, é de regionalização que estamos falando - este "recortar o espaço geográfico", análogo ao "recortar o tempo" dos historiadores (GRATALOUP, $1991)^{13}$.

Como afirma Santos (1996), o que faz a região é a "coerência funcional" (e também simbólica, poderíamos acrescentar) "que a distingue de outras entidades, vizinhas ou não" (p. 197). Mesmo com sua mudança muito rápida, constantemente retrabalhados pelos intercâmbios acelerados da globalização, os recortes regionais sempre são passíveis de identificação. Num mundo onde as ordens econômica, política e cultural aparecem ao mesmo tempo globalizadas e fragmentadas, integradas e desconectadas, e onde o "espaço natural" é representado tanto de forma estanque (em "territórios-clausura" de "reservas naturais") quanto de formas completamente indissociáveis do "espaço social" (um pouco como os "híbridos" de Latour, 1991), torna-se extremamente difícil realizar uma "síntese" entre as múlti-

\footnotetext{
12. Smith (1988:159), por exemplo, faz uma clara associação entre "diferenciação do espaço geográfico" e "divisão territorial do trabalho", como se esta fosse a única fonte da diversidade territorial.

13. Da mesma forma como ressaltamos para a regionalização, a periodização é vista pelos historiadores como uma "hipótese necessária", um instrumento de trabalho: "A divisão da história em períodos não é um fato, mas uma hipótese necessária ou um instrumento de pensamento, que vale na medida em que for esclarecedora e dependa, para sua validade, da interpretação" (CARR, 1976:54-55).
} 
plas dimensões condensadas no espaço geográfico. Daí a necessidade de regionalizar, ao mesmo tempo distinguindo e integrando essas múltiplas dimensões. Muitos autores, ao elegerem uma questão ou fenômeno social mais específico na definição de região, como ocorreu nas últimas décadas com o regionalismo (político) e a identidade (cultural) regional, resolvem esta questão limitando a abrangência do conceito, vinculado a processos bem mais restritos dentro da produção da diversidade territorial.

A questão da continuidade espacial para definir regiões ou recortes regionais envolve uma das grandes polêmicas da Geografia contemporânea, aquela sobre a relação entre território e rede ou, na linguagem de Veltz (1996), entre territóriorede e território-zona. A distribuição de fenômenos de forma mais homogênea no espaço, dentro de uma lógica "zonal" ou de continuidade, pertence à visão mais tradicional de território. Hoje, embora a lógica zonal não tenha em hipótese alguma desaparecido, torna-se cada vez mais dominante a lógica reticular, dos fluxos em rede, descontínua, que conecta apenas alguns pontos do espaço ${ }^{14}$.

Se antes a região podia ser vista de forma contínua, como unidade espacial não fragmentada, hoje o caráter altamente seletivo e muitas vezes "pontual" da globalização faz com que tenhamos um mosaico tão fragmentado de unidades espaciais que ou a região muda de escala (focalizada muito mais sobre o nível local, onde ainda parece dotada de continuidade) ou se dissolve entre áreas descontínuas e redes globalmente articuladas. Nesse caso, uma proposta interessante seria realizar uma "regionalização global em rede", onde poderíamos distinguir territórios-rede de múltiplos agentes, como os que envolvem as grandes diásporas de imigrantes, os circuitos do narcotráfico, do contrabando, do sistema financeiro, do turismo internacional etc. Eles funcionam integrados ao sistema-mundo mas têm importantes especificidades que permitem uma leitura geográfica particular de suas atuações. Numa outra escala, enfatizando os mesmos processos sociais de nossa proposta conceitual de região (HAESBAERT, 1988), porém assimilando agora o caráter fragmentado dos espaços, elaboramos a noção de rede regional para apreender os múltiplos territórios desenhados pela "rede gaúcha" no interior do Brasil (HAESBAERT, 1997).

No que se refere à estabilidade regional, como já comentamos ao citar Santos (1996), num mundo altamente volátil e onde o próprio capital seleciona e abandona espaços numa velocidade incrível, associada à tecnologia informacional, a instabilidade é na verdade o que domina. Não podemos contudo esquecer que em muitas áreas ocorre um retorno aos enraizamentos mais conservadores, através de identidades étnicas, religiosas, nacionais etc. e que este é um complicador a mais para nossas regionalizações.

\footnotetext{
${ }^{14}$ Numa leitura similar, Castells (1999) utiliza as denominações "espaço dos lugares" e "espaço das redes" para distinguir estas duas perspectivas.
} 
Por fim, no que se refere à escala privilegiada das análises regionais, podemos dizer que não há mais uma escala regional por excelência, como ocorria com a escala subnacional. Mas também parece não haver dúvida de que, por mais que os processos sociais manifestem tendência de privilegiar as escalas global e local, análises de fenômenos que se dão em escalas intermediárias ou meso-escalas continuarão sempre imprescindíveis. Como sabemos, a escala nacional, definida pelo espaço de atuação dos Estados-nações, continua muito relevante. Portanto, continuam tendo espaço para seus trabalhos aqueles geógrafos mais tradicionais que ainda definem uma escala regional de análise no nível subordinado imediatamente ao Estado-nação, identificando aí regiões subnacionais. Mas, se ainda é possível analisar regiões frente aos Estados-nações, não é frente à globalização que podemos redefinir melhor, a partir de agora, o conceito de região?

\section{A redefinição da região frente aos processos de globalização}

Se existe hoje um resgate ou uma continuidade teoricamente consistente para os estudos regionais e os métodos de regionalização, ele deve se pautar numa reconstrução do conceito de região a partir de suas articulações com os processos de globalização. Cabe-nos portanto, à guisa de conclusão, corroborar plenamente as duas afirmações de Milton Santos que abrem este artigo - a região não acabou (no título de Smith [1988]: “A região está morta. Viva a região!”), devemos empreender uma atualização do conceito e esta se dá levando em conta:

- o grau de complexidade muito maior na definição dos recortes regionais, atravessados por diversos agentes sociais que atuam em múltiplas escalas;

- a mutabilidade muito mais intensa que altera mais rapidamente a coerência ou a coesão regional;

- a inserção da região em processos concomitantes de globalização e fragmentação.

A região enquanto conceito, na interação sujeito-objeto, não pode cair nem na visão de região como algo auto-evidente a ser "descoberto" (seja como realidade "natural", seja como "algo vivo percebido pelos homens") nem como simples recorte apriorístico, definido pelo pesquisador com base unicamente nos objetivos de seu trabalho. Assumimos aqui a posição, já comentada, da região enquanto conceito, veículo de interpretação do real, e regionalização enquanto instrumento de investigação, de forma análoga ao método de periodização dos historiadores.

Região, enquanto conceito, não deve entretanto ser vista como uma simples idéia lançada pelo geógrafo como uma rede produzida na e para a sua teoria regional. Esta "rede" apreende características efetivamente existentes. A região não é apenas uma construção intelectual, ela também é efetivamente construída pela atividade humana (SMITH, 1988), em sua constante produção da diversidade territo- 
rial. Se o conceito, enquanto idéia mais elaborada e geral que temos sobre o mundo, nunca esgota o entendimento da realidade e muito menos a substitui, ele também participa dela, na medida em que sua construção acaba sempre interferindo não só na nossa leitura como também na nossa ação sobre o mundo.

A questão principal será sempre a de perceber quais são os agentes e os processos que devem ser priorizados para entender as razões da diferenciação espacial e, somente a partir daí, qual a escala em que ela se manifesta com maior clareza (ou coerência). Sintetizando, a região pode ser definida a partir de três grandes pontos de vista, sob três diferentes níveis de abrangência conceitual:

a. qualquer recorte do espaço geográfico, independente da escala ou do processo social dominante; pode ser um simples instrumento para a análise do geógrafo (ex. a região como "classe de área" na geografia neopositivista [GRIGG, 1974]) ou, no senso comum, um instrumento para referência de localização das pessoas.

b. um tipo de recorte do espaço geográfico, definido pela escala em que a diversidade territorial dos processos sociais se manifesta com maior evidência ou coesão (em sua complexidade ou elegendo-se os mais relevantes em dado momento histórico, como ocorre com a "divisão espacial do trabalho" na ótica de Massey, 1984) ${ }^{15}$

c. um determinado recorte do espaço geográfico, decorrente de fenômenos sociais próprios, não generalizáveis a todos os espaços, notadamente os regionalismos políticos e as identidades regionais (como em nossa conceituação já citada: HAESBAERT, 1988).

Com a reformulação do papel do Estado-nação e sua relativa perda de poder no ordenamento territorial desta virada de século, definir região frente ao Estadonação também se torna problemático. É verdade que ainda proliferam pelo mundo vários movimentos regionalistas que definem a região como locus destes movimentos políticos por maior autonomia frente ao Estado. Mas muitas destas regiões são também e cada vez mais espaços de articulação frente a outras escalas, mais diretamente vinculadas aos circuitos globais. Um exemplo é o da Catalunha, na Espanha, preocupada tanto em alcançar maior autonomia frente ao governo central espanhol quanto em assegurar um papel mais expressivo no contexto da União Européia e do mundo globalizado. O mesmo parece ocorrer no movimento regionalista do norte italiano, da Escócia e de Flandres, na Bélgica, movimentos regio-

\footnotetext{
15. Alguns autores, como Santos (1994), embora privilegiem um processo social na definição de regiões ("a energia que preside" a sua formação "é a das divisões do trabalho sucessivamente instaladas" [p. 98]) não reconhecem uma escala prioritária para a manifestação desta diversidade regional ("regiões são subdivisões do espaço: do espaço total, do espaço nacional e mesmo do espaço local" [p. 98]).
} 
nais que em vários momentos se transformam também em movimentos nacionais, na medida em que almejam a formação de novos Estados-nações.

Uma redefinição de região passa assim tanto pelas relações que se dão frente ao Estado-nação quanto frente aos circuitos da globalização. Como principais propostas alternativas para esta atualização conceitual reconhecemos a que destaca as relações entre os níveis local e global como relações privilegiadas na definição de região e a que admite a emergência de regiões numa nova escala regional ou mesoescala, que pode ser intra ou inter-nacional, mas também definida prioritariamente por suas relações na dinâmica global. No primeiro caso temos, por exemplo, a abordagem de Thrift (1996), no segundo caso temos a de Ohmae (1996).

Para Smith "a diferenciação regional se torna organizada cada vez mais no nível internacional do que no nível nacional; regiões subnacionais cada vez mais dão lugar a regiões da economia global" (p. 150). Ele reconhece no entanto a força dos localismos, em sentido genérico, o que inclui a diferenciação regional em escalas de menor amplitude. Ohmae (1996) radicaliza: com o "fim do Estado-nação" (ou quase) emergem "economias regionais" que estabelecem um novo padrão "ótimo" de áreas geográficas capazes de atender com maior vantagem os requisitos de um capitalismo globalizado. Surgem assim "Estados-regiões", "unidades econômicas, e não políticas", cujo "foco não tem nada de local" (p. 83) e que "têm que ser suficientemente pequenos para seus cidadãos compartilharem de interesses como consumidores, mas de tamanho suficiente para justificar economias não de escala (...) mas de serviços - infra-estrutura de comunicações, de transportes e de serviços profissionais essenciais à participação na economia global" (p. 84).

Situadas nas áreas mais dinâmicas intra ou transnacionais, sem fronteiras claras, os Estados-regiões corresponderiam à escala geográfica mais viável para a reprodução da dinâmica econômica global, acolhendo amplamente os investimentos externos e indo contra "as preocupações retrógradas do Estado-nação ao qual pertencem" (p. 74). Por mais questionável que seja esta proposta, vinda de um dos gurus da globalização, ela representa no mínimo uma evidência de novas formas de articulação espacial, para além das localizações pontuais (a disputa entre municípios, por exemplo) e impregnada dos interesses altamente seletivos da economia globalizada.

Numa outra ótica, teoricamente muito mais elaborada, Thrift (1996) afirma que "a região está se fragmentando, tornando-se não tão desorganizada (...) quanto deslocada nos termos em que costumamos considerar regiões como áreas contínuas e demarcadas" (p. 239), fragmentação que decorre tanto da seletividade da globalização quanto do reforço de identidades culturais. Neste mundo "globalmente local" ou de "localismos globalizados", os "contextos podem ser consumidos localmente (embora até isto esteja em questão) mas são cada vez menos produzidos localmente" (p. 240).

Numa série anterior de três artigos, intitulada "Por uma nova Geografia Regional", Thrift (1990, 1991, 1993) faz uma proposta bastante provocativa: reali- 
zar uma "geografia regional reconstruída" a partir do pensamento pós-estruturalis$\mathrm{ta}^{16}$. O autor afirma que, se a Geografia Regional tem um projeto teórico, este é o de "tratar as pessoas como agentes, os lugares como contextos e a causalidade como um processo iterativo de ações de movimento rápido e estruturas de movimento lento" (1991:456). Ao associar região e lugar, ele se pergunta: "O que é o lugar neste novo mundo? A resposta abreviada é suspeita: permanentemente em um estado de enunciação, entre endereços, sempre adiado. Lugares são 'estágios de intensidade', traços de movimento, velocidade e circulação" (1993:94). Bem ao contrário, nem é preciso dizer, de visões já clássicas como a de Tuan, ao afirmar que, se o espaço é "algo que permite movimento, então lugar é pausa; cada pausa no movimento torna possível que localização se transforme em lugar", esse "mundo de significado organizado" (1983:198). Significado, organização/ordenamento que cabe ao pós-estruturalismo, constantemente, desconstruir.

No nosso ponto de vista o "lugar da mobilidade" ou a "região-lugar" de Thrift, associado ao pensamento de visionários como Baudrillard e Virilio, não exclui de modo algum o "lugar da pausa" de Tuan, pois há também o lugar das grandes estruturas de mudanças mais lentas (principalmente a mega-estrutura capitalista), continua existindo o fechamento relativo e novas formas de "enraizamento". O problema crucial talvez seja o da imbricação de múltiplas lógicas num mesmo espaço: entre os extremos, hibridismos e neofundamentalismos podem aparecer dentro de uma única área, dependendo da relação entre os atores ali presentes ${ }^{17}$. Mobilidade e hibridismo são duas características muito importantes mas não suficientes para reler o lugar e a região.

Se, como afirma Thrift, "temos que teorizar a identidade como uma distribuição no espaço-tempo de sujeitos-contextos híbridos que são constantemente copiados, que são constantemente revisitados, sentenciados e enunciados" (1993:96), precisamos também dar conta daquelas identidades/espaços em que os sujeitos não permitem a hibridização e ainda percorrem um processo muito mais de "tradição" do que de "tradução" cultural, nos termos de Hall (1996).

Quanto a este "novo localismo", não podemos nos contentar com a leitura fragmentadora do pós-estruturalismo. O marxismo ainda tem contribuições muito importantes, e não apenas na sua leitura privilegiada, a da dimensão econômica do

\footnotetext{
16. De forma muito simplificada podemos dizer que o pós-estruturalismo (para alguns sinônimo de pós-modernismo e desconstrutivismo), de raízes francesas (Bataille, Derrida, Deleuze, Guattari, Lyotard) mas de difusão muito maior na geografia anglo-saxônica, se caracteriza por enfatizar o devir (o "tornar-se"), a pluralização/diferenciação, a multiplicidade de interpretações e a hibridização.

17. Assim, no próprio Afeganistão dos talibãs, protótipo do reenraizamento e do territorialismo (o fechamento em um território segregado), temos ao mesmo tempo a lógica dominante, que impõe regras extremamente rígidas no uso e no controle do espaço, seccionando o espaço do homem e da mulher, contendo ou filtrando toda influência externa, e uma lógica mais extrovertida, aquela que envolve os traficantes de drogas e de armas e suas redes globalmente conectadas.
} 
espaço. Smith (1988) afirma que o localismo representa "uma 'desestruturação' da coerência geográfica que dominava a expansão econômica na maior parte do mundo do pós-guerra, uma destruição da velha estrutura regional", resultado de intensa competição num novo modo de regulação moldado pelas teses neoliberais pós-fordistas. Para ele, numa crítica às vezes demasiado negativa, bem ao contrário das teses pós-modernistas da "política da diferença", o localismo corresponderia hoje a uma "política reacionária de impasse" em que "as velhas regras estão desaparecendo e as novas, longe de serem evidentes, são o objeto da luta política". Não podemos assim restringir a vida cotidiana simplesmente ao "localismo", transformado em "apriorismo filosófico que privilegia o local sobre todas as outras escalas espaciais” (SMITH, 1988:151). Como nos anos 30, por trás desse localismo podem estar emergindo novas reestruturações regionais.

Ao apresentar de forma sintética as proposições de uma "região-Estado" (invertendo o termo de Ohmae) e uma "região-local" (e também "lugar", na visão de Thrift), nosso objetivo é simplesmente o de encerrar este artigo ao mesmo tempo buscando respostas e abrindo novas questões, ou seja, estimulando a polêmica numa temática que ainda tem muito a ser discutido.

Acreditamos ter avançado ao problematizar o novo contexto em que se desdobram as questões regionais, especialmente no âmbito da Geografia. Isto tanto se continuarmos enfatizando a coerência regional nos moldes dos territórios-zona, dotados de continuidade (porém priorizando agora o nível local, especialmente em suas relações com o global), quanto se assumirmos uma nova análise regional a partir dos territórios-rede, fisicamente descontínuos mas com fortes conexões internas (na conformação de "redes regionais").

Fica evidente a relevância dos estudos regionais e a necessidade permanente de analisar a produção da diversidade territorial, seja região ou outro o nome que dermos para os recortes que ela produz. Porque mais do que avaliar um conceito o que importa é reconhecer a natureza dos novos-velhos processos que constróem o espaço geográfico, neste jogo indissociável entre des-igualdade e diferença - a primeira, centro da geografia marxista, a segunda, fundamento de uma geografia pósmoderna e/ou pós-estruturalista.

\section{REGIÃO, DIVERSIDADE TERRITORIAL E GLOBALIZAÇÃO}

Resumo: A região e a questão regional seguem sendo relevantes e são revigoradas, pois mesmo na era da globalização a diversidade territorial se manifesta tanto através de profundas desigualdades (econômicas) - que o marxismo ajuda a explicar, quanto de diferenças (culturais), sobrevalorizadas pelo chamado pós-estruturalismo. Neste jogo de múltiplos desenhos territoriais, a relação local-global adquire destaque e a região se torna muito mais complexa, manifestando-se tanto na forma tradicional dos territórios-zona quanto na forma de territórios-rede ou "redes regionais".

Palavras-chave: Região, Regionalização, Global-Local.

\section{REGION, TERRITORIAL DIVERSITY AND GLOBALIZATION}

Summary: Region and regional question are still notables and they are being reinvigorated, as even in the globalization era the territorial diversity appears by deep (economic) inequalities - 
explained mainly in marxist terms, and by (cultural) differences, overemphasized by the poststructuralism. At this game of multiple territorial designs, the global-local relation is emphasized and region becomes much more complex, appearing in the traditional form of zonal-territories as well as in the form of network-territories (or "regional networks").

Keywords: Region, Regionalization, Global-Local.

\section{BIBLIOGRAFIA}

ALBUQUERQUE, E. (1998): O conceito de região aplicado a estados federais: o caso do Rio Grande do Sul. Dissertação de Mestrado, São Paulo: USP.

BERGSON, H. (1989) [1934]: O Pensamento e o Movente (Introdução). In: Os Pensadores: William James e Henri Bergson. São Paulo: Nova Cultural.

(1993) [1927]: Essai sur les données immédiates de la conscience. Paris: PUF.

BOUDEVILLE, J. (1972): Aménagement du territoire et polarisation. Paris, PUF. BOURDIEU, P. (1989): O Poder Simbólico. Lisboa e São Paulo: Difel e Bertrand Brasil. (cap. A identidade e a representação: elementos para uma reflexão crítica sobre a idéia de região).

CANCLINI, N. (1997) [1992]: Culturas Híbridas. São Paulo: EdUSP.

CARR, E. (1976) [1961]: Que é história? Rio de Janeiro: Paz e Terra.

CASTELLS, M. (1999): A Sociedade em Rede. Rio de Janeiro: Paz e Terra.

CASTRO, I. (1992): O Mito da Necessidade: discurso e prática do regionalismo nordestino. Rio de Janeiro: Bertrand Brasil.

CLAVAL, P. (1993): Iniciation à la Géographie Régionale. Paris: Nathan.

CORRÊA, R. (1986): Região e Organização Espacial. São Paulo: Ática.

(1994): Região: globalização, pluralidade e persistência conceitual. Anais do $5^{\circ}$ Congresso Brasileiro de Geógrafos. Vol. 1. AGB: Curitiba, pp. 209-226

DOLLFUS, O. (1993): Geopolítica do Sistema-Mundo. In: Santos, M. et al. (orgs.) Fim de Século e Globalização. São Paulo: HUCITEC-ANPUR.

ENTRIKIN, N. (1990): The betweeness of place. Londres: Sage.

(1994): Place and region. Progress in Human Geography, vol. 18.

FRÉMONT, A. (1976): La région: espace vécu. Paris: Flammarion. (2a. ed. 1999; ed. portuguesa: A região, espaço vivido. Coimbra, Almedina, 1980).

GIBSON, K. (1998): Social polarization and the politics of difference: discourses in colision or collusion? In: Fincher, R. e Jacobs, M. (eds.) Cities of Difference. New York: Guilford Publications.

GIDDENS, A. (1991) [1990]: As Conseqüências da Modernidade. São Paulo: EdUNESP.

GILBERT, A. (1988): The New Regional Geography in English and French-speaking Countries. Progress in Human Geography, 12 (2).

GOMES, P. (1988): As razões da região. Rio de Janeiro: UFRJ (Dissertação de Mestrado). 
(1995): O conceito de região e sua discussão. In: Castro, I. et al. (orgs.) Geografia: Conceitos e Temas. Rio de Janeiro: Bertrand Brasil.

(1996): Geografia e Modernidade. Rio de Janeiro: Bertrand Brasil.

GRAMSCI, A. (1987): A Questão Meridional. Rio de Janeiro: Paz e Terra.

GRATALOUP, C. (1991): Les régions du temps. In: Périodes: la construction du temps historique. Paris: Editions de l'EHESC e Histoire au Présent.

HAESBAERT, R. (1988): RS: Latifúndio e Identidade Regional. Porto Alegre: Mercado Aberto.

(1995): Desterritorialização: entre as redes e os aglomerados de exclusão. In: Castro, I. et al. (orgs.) Geografia: Conceitos e Temas. Rio de Janeiro: Bertrand Brasil.

(1997): Des-territorialização e Identidade: a rede "gaúcha” no Nordeste. Niterói: EdUFF.

(1998): Globalização e fragmentação no mundo contemporâneo. In: Haesbaert, R. (org.) Globalização e Fragmentação no Mundo Contemporâneo. Niterói, EdUFF.

HALL, S. (1997) [1992]: Identidades Culturais na Pós-modernidade. Rio de Janeiro: DP\&A.

HARTSHORNE, R. (1939): The Nature of Geography. Washington: Association of American Geographers.

(1978) [1959]: Propósitos e Natureza da Geografia. São Paulo: Hucitec.

HARVEY, D. (1989): A Condição da Pós-modernidade. São Paulo: Loyola.

HAUER, J. (1990): What about regional geography after structuration theory? In: Johnston, R. et al. (eds.) Regional Geography: current developments and future prospects. Londres/Nova York: Routledge.

HEIDRICH, A. (1999): Região e regionalismo: observações acerca dos vínculos entre a sociedade e o território em escala regional. Boletim Gaúcho de Geografia n. 25. Porto Alegre: AGB.

HERBERTSON, A. (1905): The major natural regions: an essay in systematic geography. Geographical Journal, março.

LACOSTE, Y. (1976): La Géographie, ça sert d'abord à faire la guerre. Paris: Maspero. (ed. brasileira: 1988. A Geografia, isto serve em primeiro lugar para fazer a guerra. Campinas: Papirus)

LATOUR, B. (1991): Nous n'avons jamais été modernes. Paris: La Découverte. (ed. brasileira: Jamais fomos modernos. Rio de Janeiro: Ed. 34,1994)

LEPETIT, B. (1998) [1996]: Sobre a escala na história. In: Revel, J. (org.) Jogos de escalas: a experiência da microanálise. Rio de Janeiro: Ed. Fund. Getúlio Vargas.

LÉVY, J. et al. (coord.) (1999): Mondialisation: les mots et les choses. Paris: Karthala.

MARKUSEN, A. (1981): Regionalismo: uma abordagem marxista. Espaço e Debates 1(1). São Paulo: Cortez. 
(1987): Regions: the economics and politics of the territory. Totowa: Rowman \& Littlefield.

MASSEY, D. (1984): Spatial Divisions of Labour. N. York: Routledge.

McGINNIS, M. (ed.) (1999): Bioregionalism. Londres/Nova York: Routledge.

MOREIRA, R. (1997): Da região à rede e ao lugar. AGB-Bauru: Ciência Geográfica $\mathrm{n}^{\circ} 6$.

OHMAE, K. (1996): O fim do Estado-nação: a ascenção das economias regionais. Rio de Janeiro: Campus.

RAFFESTIN, C. (1993) [1980]: Por uma Geografia do Poder. São Paulo: Ática.

ROBERTSON, R. (1995): Glocalization: Time-Space and HomogeneityHeterogeneity. In: Featherstone, M. et al. (eds.) Global Modernities. Londres: Sage Publications.

SACK, R. (1986): Human Territoriality. Cambridge: Cambridge University Press.

SANTOS, M. (1994): Técnica, Espaço, Tempo: Globalização e meio técnico-científico informacional. São Paulo: Hucitec.

(1999): Modo de produção técnico-científico e diferenciação espacial. Território n. 6. Rio de Janeiro: UFRJ/Garamond.

SAUER, C. (1998) [1925]: A morfologia da paisagem. In: Corrêa, R. e Rosendhal, Z. (orgs.) Paisagem, Tempo e Cultura. Rio de Janeiro: EdUERJ.

SMITH, N. (1988): The region is dead! Long live the region! Political Geographical Quarterly. Vol. 7, n. 2, abril. Newcastle-upon-Tyne: Depto. de Geografia.

STORPER, M. (1997): The Regional World. Nova York: Guilford.

SWINGEDOUW, E. (1992): The Mammon quest; 'Glocalization', interspatial competiton and the monetary order: the construction of new scales. In: Dunford, M. e Kafkalas, G. (orgs.) Cities and regions in the new Europe. Londres: Belhaen Press.

THRIFT, N. (1990, 1991, 1993): For a new regional geography 1, 2, 3. Progress in Human Geography vol. 14, 15 e 17.

(1996): Visando o âmago da região. In: Gregory, D. et al. (orgs.) Geografia Humana. Rio de Janeiro: Jorge Zahar.

TUAN, I.F. (1983) [1977]: Espaço \& Lugar. São Paulo: DIFEL.

VELTZ, P. (1996): Mondialisation, Villes et Territoires. Paris: PUF.

VIDAL DE LA BLACHE, P. (1994) [1903]: Tableau de la Géographie de la France. Paris: La Table Ronde.

(1954) [1921]: Princípios de Geografia Humana. Lisboa: Edições Cosmos. 